\title{
STRUCTURAL ASSESSMENT OF A SPACE STATION SOLAR DYNAMIC HEAT RECEIVER THERMAL ENERGY STORAGE CANISTER
}

\author{
R.L. Thompson, T.W. Kerslake, ${ }^{*}$ and M.T. Tongt \\ Structural Mechanics Branch \\ NASA Lewis Research Center
}

\begin{abstract}
Advanced analytical tools and experimental techniques were recently developed in the Structural Mechanics Branch to assess the structural performance of a space station thermal energy storage (TES) canister subjected to orbital solar flux variation and cold startup operating conditions. Included in the assessment were the impact of working fluid temperature and salt-void distribution on the canister structure. Both analytical and experimental studies were conducted to determine the temperature distribution in the canister. Subsequent three-dimensional, nonlinear, finite-element, structural analyses of the canister were performed using both analytically and experimentally obtained temperatures. For the lack of a better material constitutive mode1, the Arrhenius creep law was incorporated into the procedure, using secondary creep data for the canister material, Haynes-188 alloy. The predicted cyclic creep-strain accumulations at the hot spot were used to assess the structural performance of the canister. Structural tests on a canister were also conducted. This was a cooperative program with the Space Station Solar Dynamic Power Module Division, Power Conversion and Heat Receiver Branch.
\end{abstract}

* Solar Dynamic Power Module Division, NASA Lewis Research Center.

†Sverdrup Technology, Inc., Lewis Research Center Group, NASA Lewis Research Center. 
As part of the Phase II option of the space station, an additional pqwer requirement of 50 kilowatts will be met by two high-efficiency solar dynamic (SD) power modules. NASA Lewis Research Center has chosen the Closed Brayton Cycle (CBC) for the Space Station SD power modules. The solar dynamic modules employ a concentrator to collect and focus incident solar flux onto the wall of a cylindrical cavity-type heat receiver where it is converted to thermal energy. A fraction of the thermal energy is transferred to a circulating working fluid to operate the heat engine and produce electrical power. The remaining thermal energy melts a eutectic composition LiF-CaF 2 salt in thermal energy storage (TES) canisters integral with the receiver cavity. The salt stores and releases thermal energy by undergoing phase changes at its melting point of $767^{\circ} \mathrm{C}\left(1413^{\circ} \mathrm{F}\right)$. This permits continuous operation of the Brayton heat engine during insulation and eclipse periods of the orbit. Shown are the solar dynamic power module and a cutaway of the solar receiver assembly.

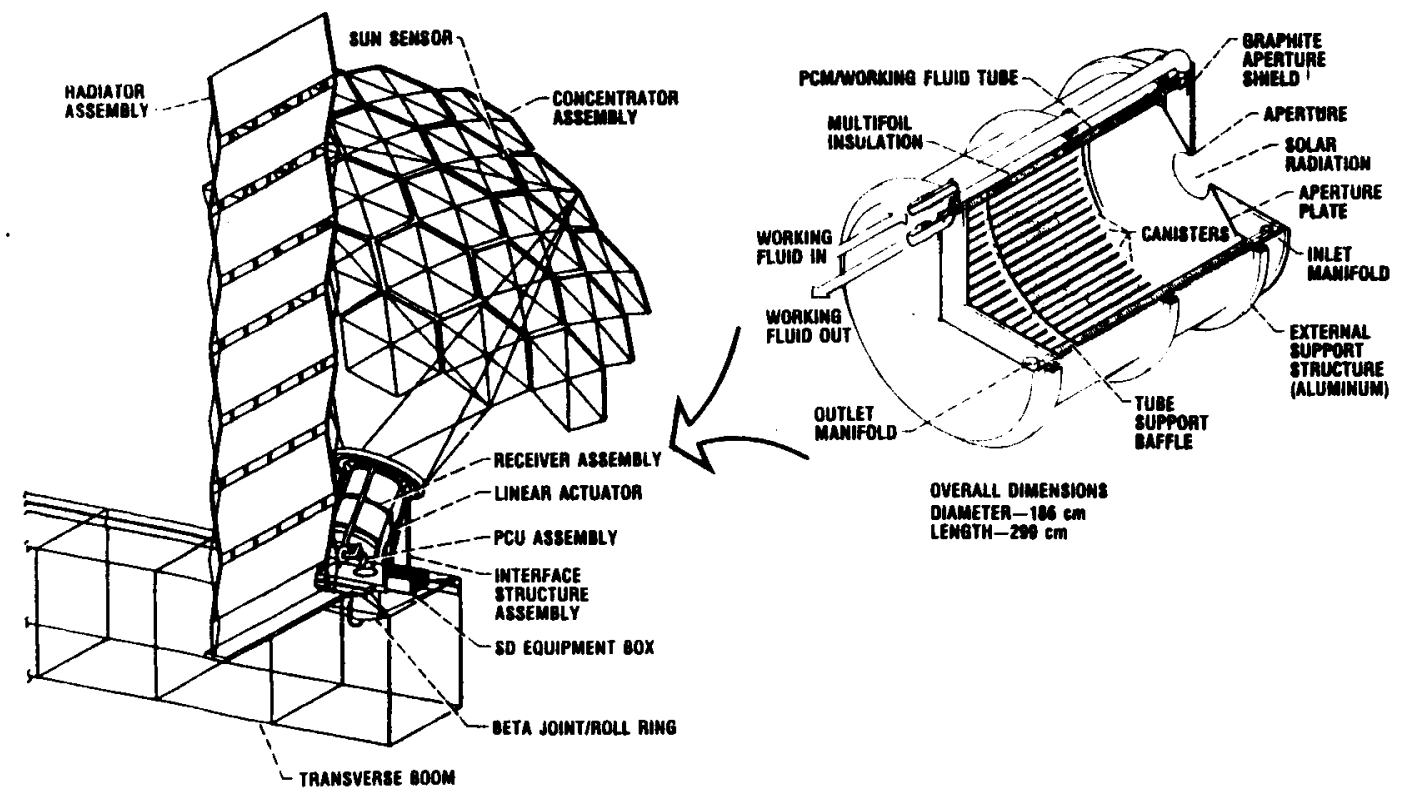

CD-88-32496 
The space station orbit under consideration is a minimum insulation orbit. It has a period of 91 minutes, with 37 minutes eclipse and a solar constant of $1323 \mathrm{w} / \mathrm{m}^{2}\left(420 \mathrm{Btu} / \mathrm{hr} / \mathrm{ft}^{2}\right)$. During each orbital cycle, the canister is subjected to appreciable transient thermal loads. Inelastic deformation can be induced in localized regions leading to potential structural failure. Assessment of durability requires reasonably accurate calculation of the structural response under cyclic loading. This problem is an ideal case in which to apply the recently developed analytical tools and procedures developed at NASA Lewis.

The canister under consideration was located $1143 \mathrm{~mm}(3.75 \mathrm{ft})$ behind the receiver focal plane - the location believed to have the most severe thermal environment. It is made of Haynes-188 alloy, and was designed by the NASA Lewis Phase B Space Station contractor team of Rockwell International Rocketdyne Division and Garrett Corporation-AiResearch (Anon., 1986). The canister under study is shown here.

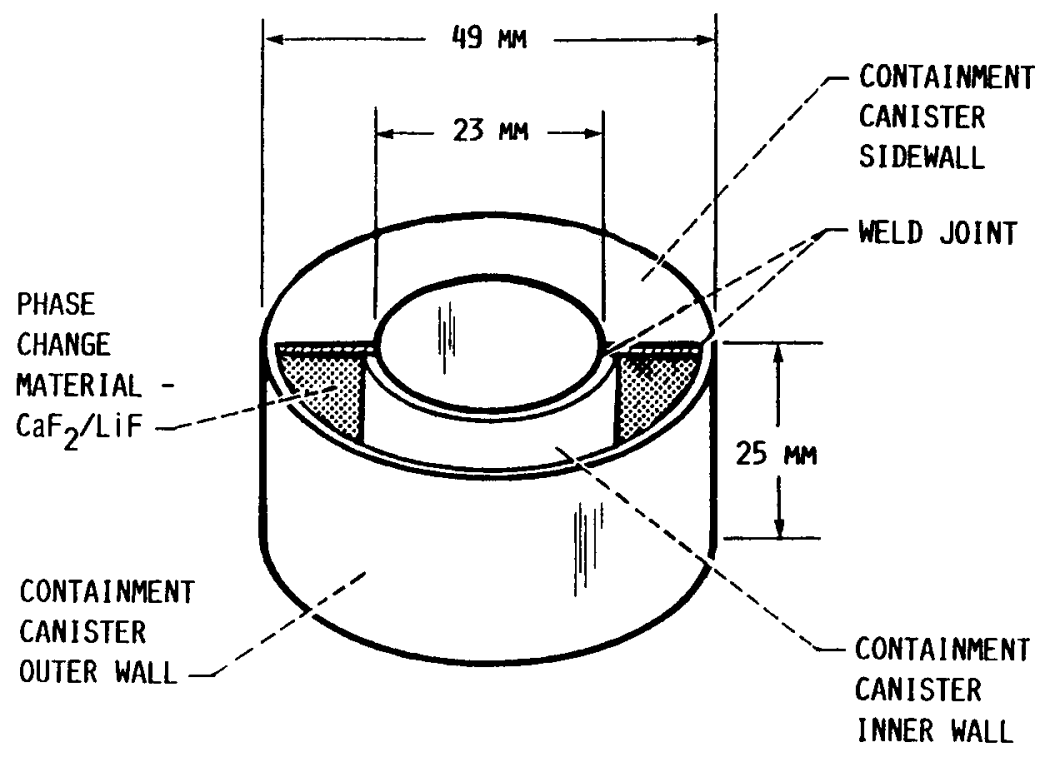


A canister with the LiF-CaF2 salt in its solidified state is shown here. The void is approxinately 25 percent of the total volume. As the solar flux heats the salt, the salt liquefies and fills the canister volume. The liquefaction process is extremely complex, particularly in a microgravity environment where the surface tension induced flow phenomenon is the driving mechanism for convection. Because the liquefaction process is not predictable, several worstcase conditions were assumed in order to determine the structural performance of the canister.

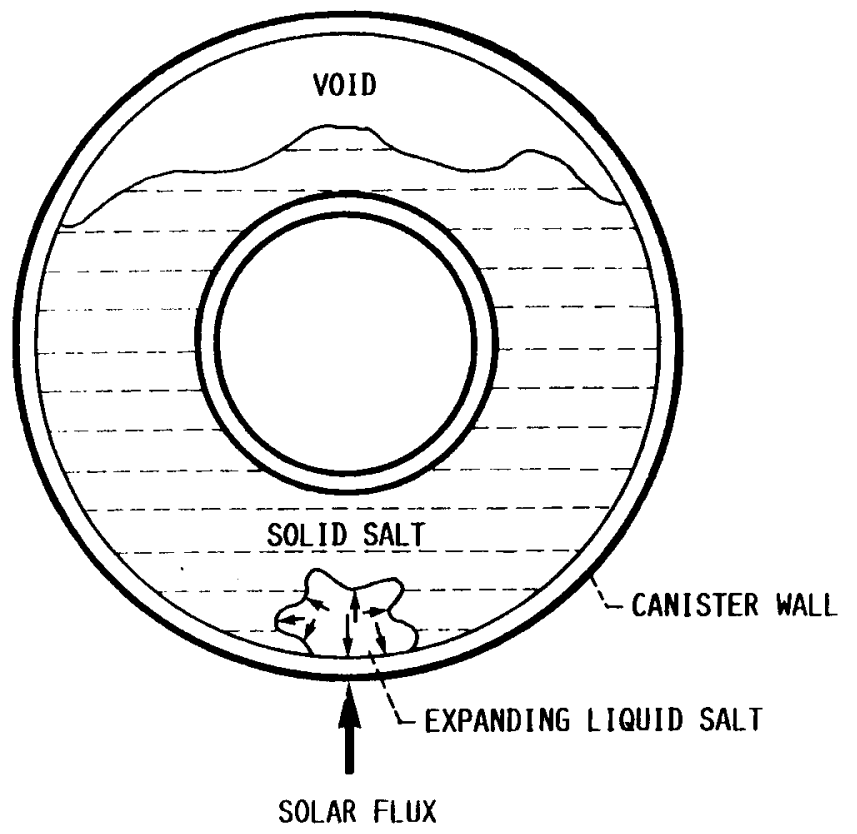


Because the exact salt formation in the canister under microgravity is not quantified, several different canister-salt configurations were analyzed to determine the effect of salt-void distribution on the canister structure. The configurations evaluated for the steady-state analyses are (a) canister filled with salt, (b) canister with an entrapped liquid pocket, (c) canister with circumferential void at the canister outer-diameter wall, and (d) canister with void at the sidewall. These configurations are shown below. Three-dimensional finite-element thermal and structural analyses of the canister were performed using the MARC finite-element program (Anon., 1984).

Subsequent nonlinear transient analyses were performed to obtain the cyclic stress-strain history for structural assessment of the canister. A canistersalt configuration with circumferential void at the outer-diameter wall was chosen for the transient analyses because steady-state analyses showed it to be the most severe case. A total of four transient analytical cases were studied to determine how the structural performance of the canister was affected by void in the canister, working fluid temperature, and cold startup operating condition.

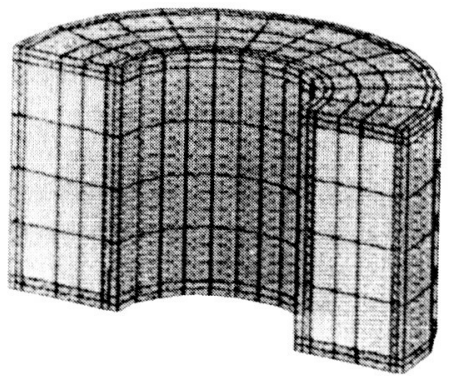

CANISTER FILLED WITH SALT

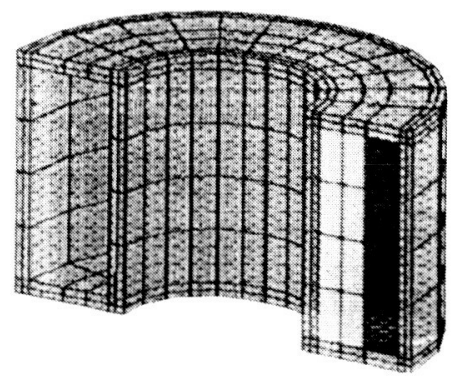

CANISTER WITH LIQUID POCKET

- 672 8-NODE SOLID ELEMENTS

- 936 NODES

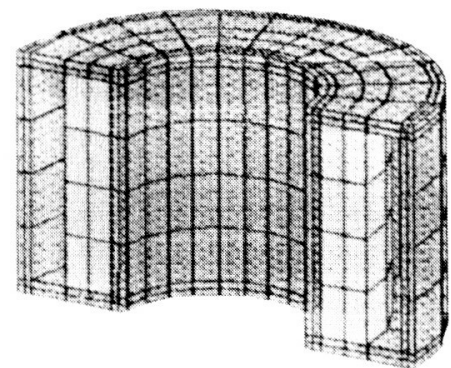

CANISTER WITH CIRCUMFERENTIAL VOID

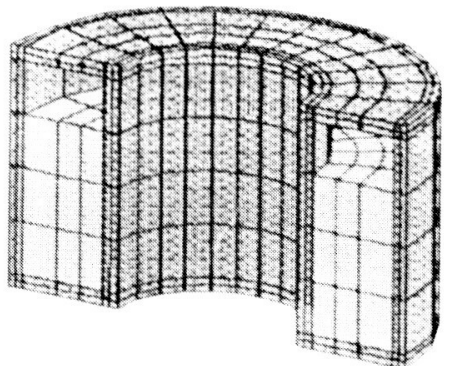

CANISTER WITH VOID AT SIDEWALL

CD-88-32499 
Steady-state thermal boundary conditions were the maximum solar heat flux of $19.9 \mathrm{kw} / \mathrm{m}^{2}\left(6300 \mathrm{Btu} / \mathrm{hr} / \mathrm{ft}^{2}\right)$ distributed according to the canister projected surface area, working fluid temperature of $704^{\circ} \mathrm{C}\left(1300{ }^{\circ} \mathrm{F}\right)$, and thermal radiation at the backwall. Based on these boundary conditions, metal temperatures were predicted by using MARC and were then used in the structural analyses. Determination of transient thermal loads was based on the transient orbital heat flux shown below. Other transient thermal boundary conditions were the working fluid temperature histories and backwall temperature histories. The phase change of $\mathrm{LiF}-\mathrm{CaF}_{2}$ salt was also considered in the analyses. The calculated canister temperature histories were then used in the structural analyses of the canister.

91-MINUTE MINIMUM ISOLATION ORBIT

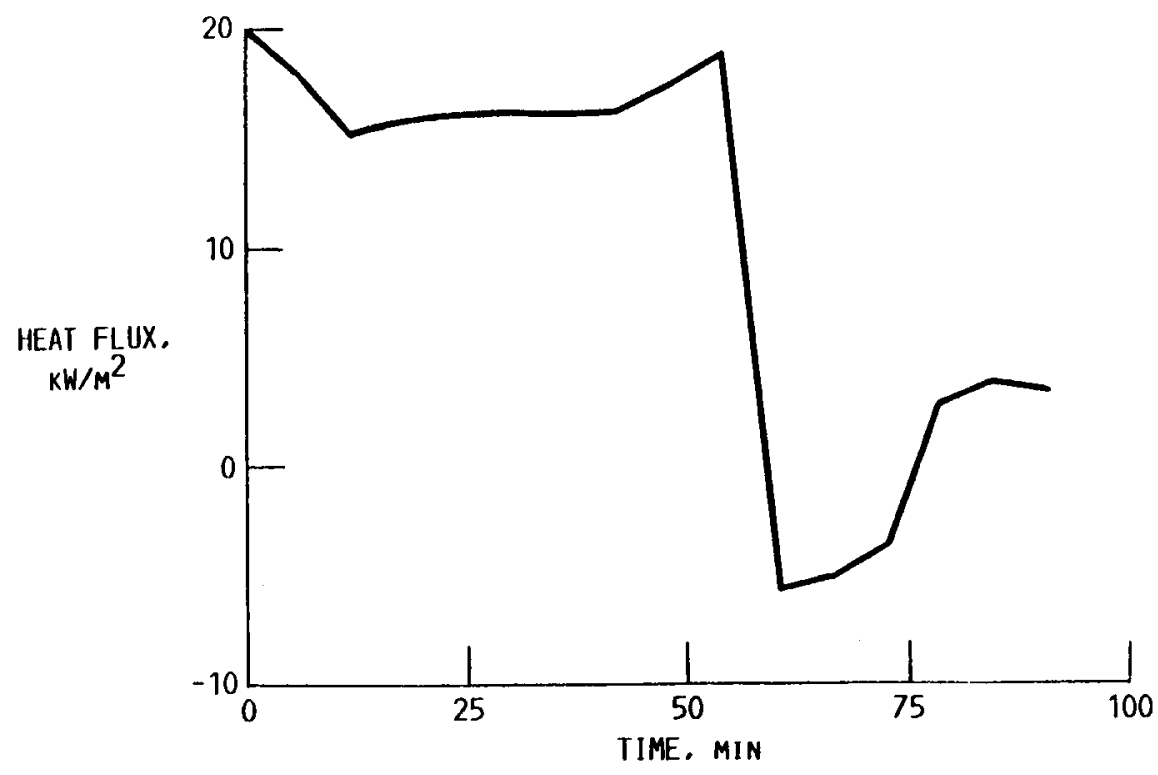

CO-88-32500 
Typical steady-state temperatures and resulting stress distributions are shown for the case of a circumferential void at the canister outer diameter wall. The hot spot is at the point of maximum solar flux. The temperature at this location is $891{ }^{\circ} \mathrm{C}\left(1630^{\circ} \mathrm{F}\right)$. The maximum Von Mises stress of $52 \mathrm{MPa}(7568$ psi) occurs at the corners of the canister, as indicated in the figure. Since steady-state analyses showed that creep would be the predominant damage mode (ignoring oxidation and hot corrosion), an Arrhenius creep law was incorporated into the MARC code by means of a user subroutine.

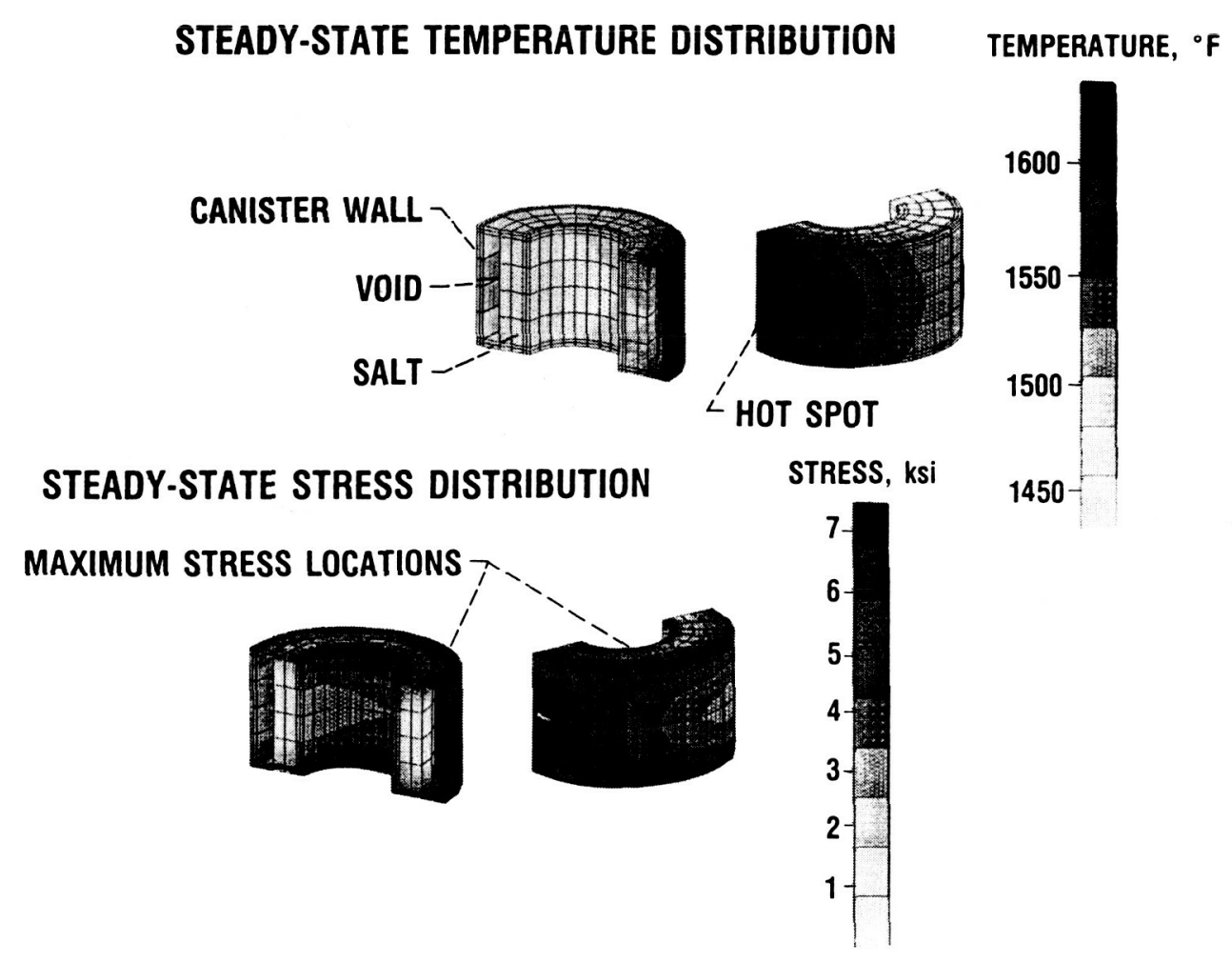

ORIGINAL PAEE IS

OF POOR QUALTTM 
Typical transient temperatures and resulting creep strains are shown for the case of a circumferential void at the canister outer-diameter wall. The temperatures and creep strains for the minimum insulation orbit are plotted at the location indicated on the figure. The working fluid temperature ranged from 980 to $1280^{\circ} \mathrm{F}$. Using the predicted temperatures and strains, thermomechanical tests on Haynes-188 specimens have been conducted to determine if the stress predictions are accurate and also to determine the effects of thermomechanical cycling and possible ratcheting of the material. These tests, conducted in the NASA Lewis High Temperature Fatigue and Structures Facility, are unique to this effort.

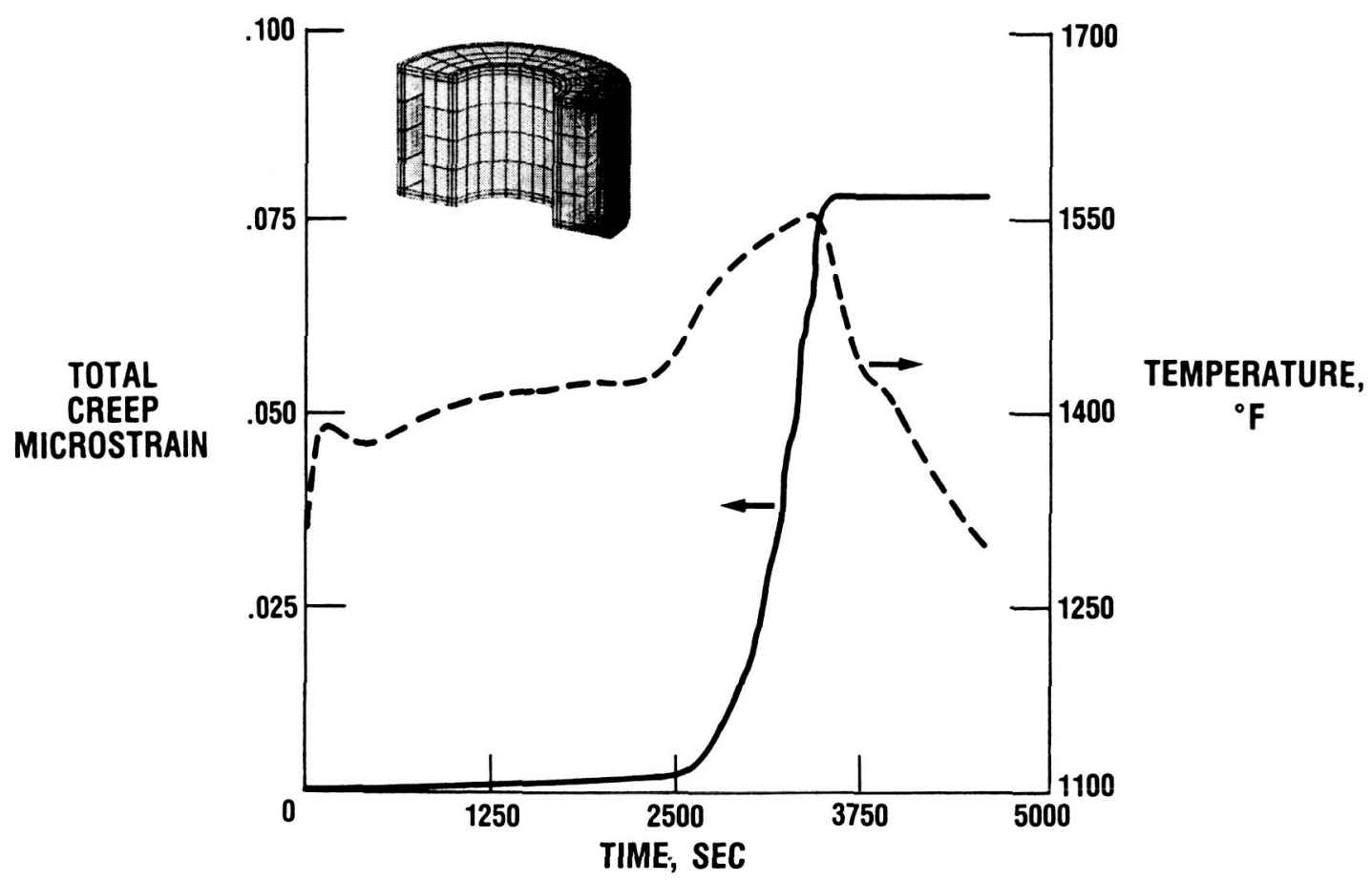

CD-88-32502 
Three canister test articles were used in the testing program. Each canister was instrumented with chromel-alumel thermocouples and radiation shields. The canisters were tested individually using a bench-top rig. The test article was slip-fitted onto a Haynes -188 pipe and was enclosed in an insulated test chamber that provided a high-temperature environment representative of the heat receiver cavity. A solar simulator, consisting of high flux quartz lamps, was also enclosed in the test chamber to irradiate the bottom half of the canister exterior surface. The dual loop power controller was programmed to automatically produce the expected orbital heat flux variation for the minimum insulation orbit described above. Preheated air flow, which simulated the engine working fluid, provided the convective cooling to the canister interior surface. The experimental objectives were twofold:

1. to demonstrate the structural adequacy of the TES canister under several worst-case heating and salt configuration conditions.

2. to determine canister temperature distributions in sufficient detail to support finite-element structural analyses for several known canister salt configurations.

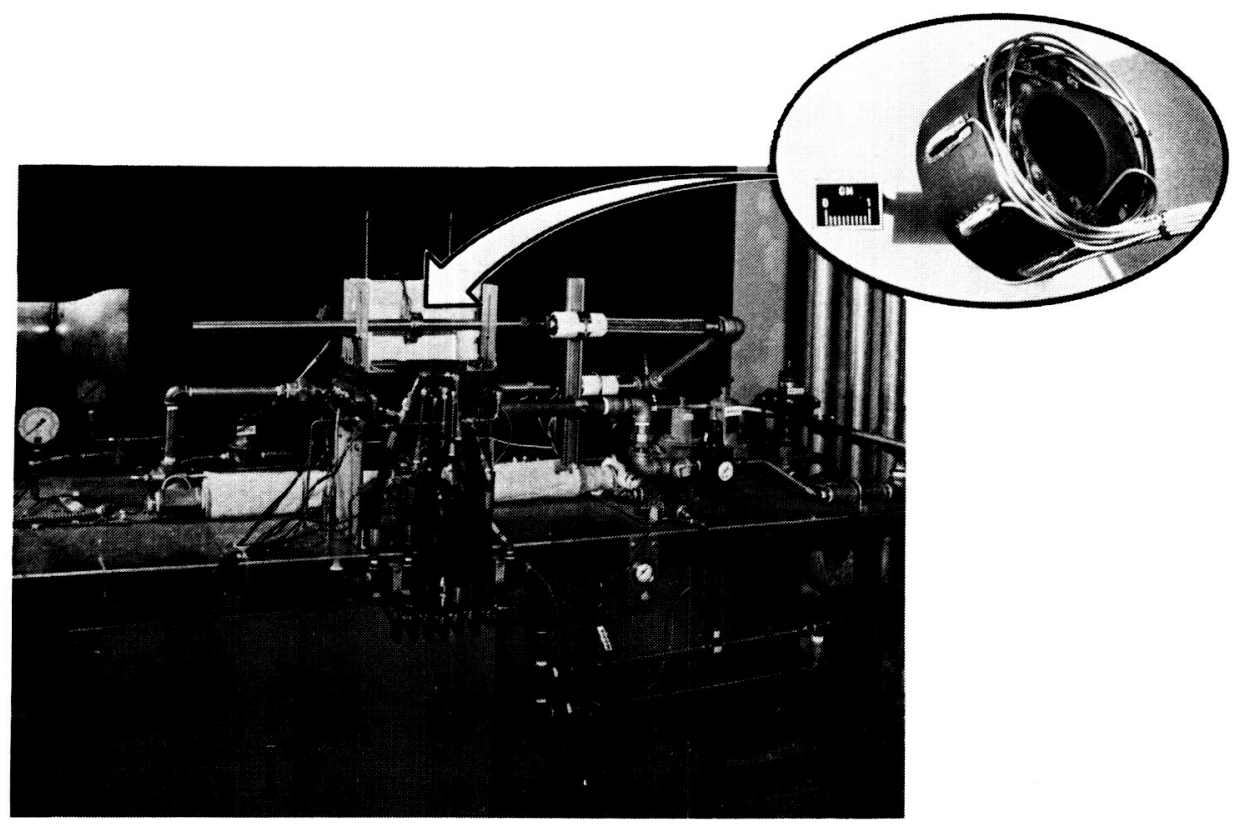


Cold startup and cyclic tests were conducted to simulate the operation of the canister under on-orbit receiver startup and orbital cyclic heat flux conditions, respectively. The effect of salt distribution on canister temperature profiles was evaluated by testing canisters with three different salt configurations. Cold startup canister tests were conducted by subjecting the test article (at ambient temperature) to a step-input of maximum heat flux without internal cooling airflow. This procedure was developed to simulate only the first 15 to 30 minutes of the receiver startup cycle - the time period believed to have the highest canister temperature gradients and highest canister salt traction forces. Canister temperature response was measured until steady-state conditions were approached (about 20 minutes). Cyclic canister tests were conducted by subjecting the test article to a series of high-low step heat fluxes. Cooling airflow rate and temperature were established at the beginning of each test and held constant throughout the testing period (10 simulated orbits or about 15 hours). All three canisters were inspected before and after each test for signs of deformation, cracks, or leaks. Inspection was performed nondestructively through the use of dye penetrant tests, $x$-ray radiography, and visual inspection. Canister dimensions were also measured to quantify deformation. Typical measured temperatures for a cyclic run are shown for four thermocouple locations. These temperatures are in reasonably good agreement with predicted temperatures.

\section{THERMOCOUPLE LOCATION}

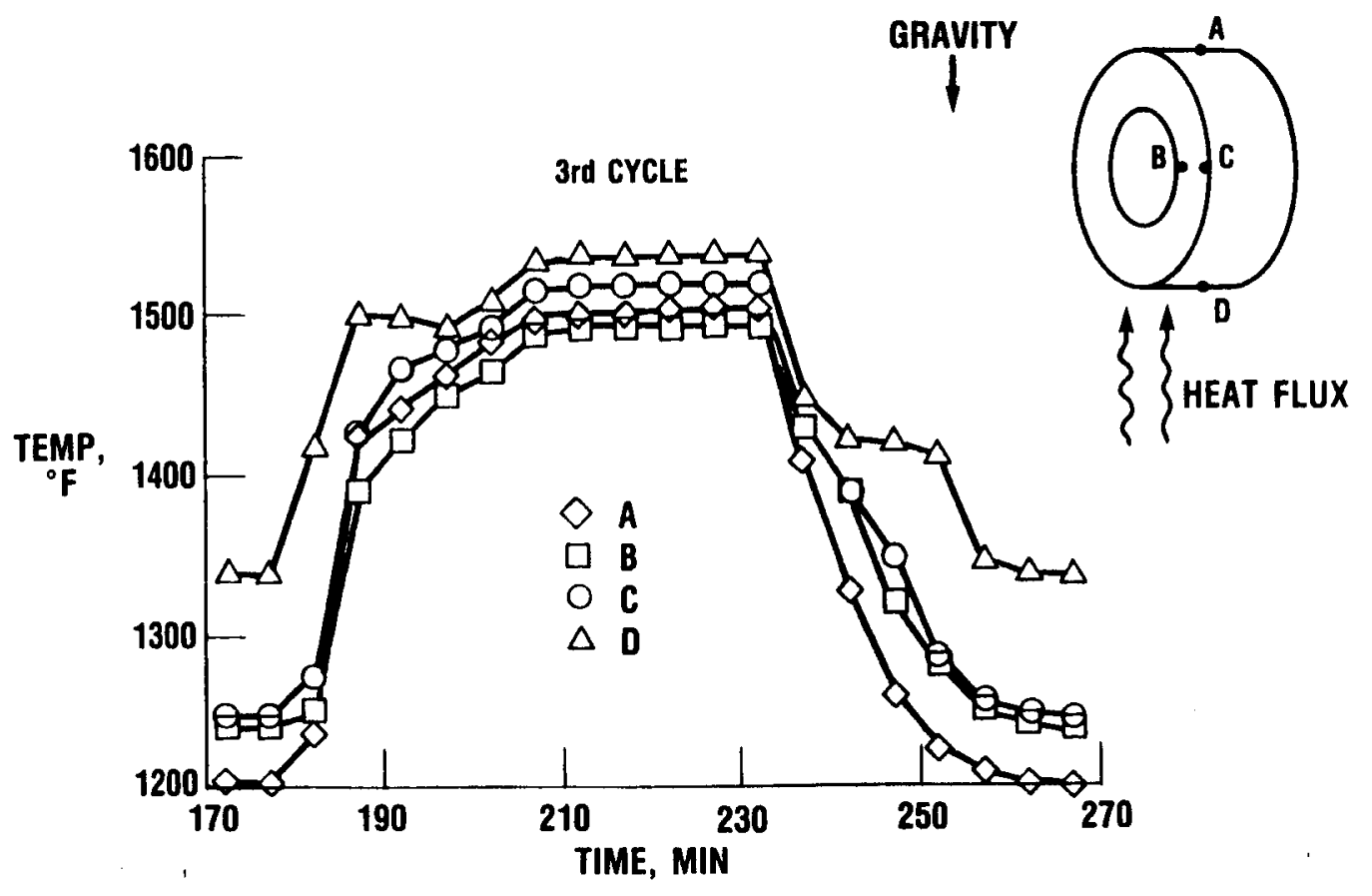

CD-88-32504 
Results of steady-state thermal and elastic structural analyses for the four canister/salt configurations are summarized below. Typical canister hot spot and maximum stress locations were shown in an earlier figure. As expected, the canister wall hot spot was located in the region of maximum heat input. The maximum stress location was at the canister side wall outer diameter. Among the four cases studied, the canister-salt configuration with circumferential void at the outer-diameter wall had the highest stress level, $52 \mathrm{MPa}$ at $891{ }^{\circ} \mathrm{C}$ $\left(7568 \mathrm{psi}\right.$ at $1635^{\circ} \mathrm{F}$ ). In all cases, however, the maximum stress level was well below the yield strength of the Haynes-188 alloy, $262 \mathrm{MPa}$ at $871{ }^{\circ} \mathrm{C}$ $\left(38000 \mathrm{psi}\right.$ at $1600^{\circ} \mathrm{F}$ ). This indicates an insignificant amount of material plasticity. However, creep deformation could occur because of long-time exposure to the receiver environment.

\begin{tabular}{|c|c|c|c|c|}
\hline \multicolumn{1}{|c|}{$\begin{array}{c}\text { Analytical } \\
\text { case }\end{array}$} & \multicolumn{2}{|c|}{ Maximum temperature } & \multicolumn{2}{c|}{ Maximum von Mises stress } \\
\cline { 2 - 5 } & ${ }^{\circ} \mathrm{C}$ & ${ }^{\circ} \mathrm{F}$ & $\mathrm{MPa}$ & $\mathrm{psi}$ \\
\hline $\begin{array}{c}\text { Canister filled } \\
\text { with salt }\end{array}$ & 862 & 1583 & 40 & 5823 \\
$\begin{array}{c}\text { Canister with } \\
\text { circumferential } \\
\text { void at 0.D. wa11 }\end{array}$ & 891 & 1635 & 52 & 7568 \\
$\begin{array}{c}\text { Canister with } \\
\text { entrapped 1iquid } \\
\text { salt pocket }\end{array}$ & 862 & 1583 & 41 & 5976 \\
$\begin{array}{c}\text { Canister with void } \\
\text { at sidewall }\end{array}$ & 868 & 1594 & 42 & 6164 \\
\hline
\end{tabular}


Results from the transient analyses are summarized below. The accumulated creep strain per cycle at the critical location (the hot spot, as noted earlier) is the most crucial parameter to consider. This value is tabulated for several different configurations of salt-void within the canister. For lack of better knowledge of the constitutive material properties of the Haynes -188 alloy, an Arrhenius steady-state creep law was used. As seen from the table, the calculated creep strain is highly dependent upon the void configuration. This dependency arises because the void affects the heat conducted from the canister wall to the salt and onto the working fluid. A void interferes with the heat path, thus causing an increased thermal stress. This higher thermal stress increases the resultant creep strain dramatically. Higher working fluid temperatures also increase the calculated amount of creep strain per cycle. The time required to accumulate one percent creep strain is also indicated in the table.

\begin{tabular}{|c|c|c|}
\hline Case & $\begin{array}{l}\text { Total accumulated creep } \\
\text { microstrain per cycle }\end{array}$ & $\begin{array}{c}\text { Amount of time to } \\
\text { accumulate } 1 \text { percent } \\
\text { creep }\end{array}$ \\
\hline $\begin{array}{l}\text { Canister filled with } \\
\text { salt, } 527 \text { to } 693^{\circ} \mathrm{C} \\
\text { working fluid } \\
\text { temperature }\end{array}$ & 0.0018 & 960 years \\
\hline $\begin{array}{l}\text { Canistel: with } \\
\text { circumitcrential void } \\
\text { at } 0 . \mathrm{D} \text {. wall, } 527 \text { to } \\
693{ }^{\circ} \mathrm{C} \text { working fluid } \\
\text { temperature }\end{array}$ & .0760 & 23 years \\
\hline $\begin{array}{l}\text { Canister with } \\
\text { circumferential void } \\
\text { at } 0 . \mathrm{D} \text {. wall, } 613 \text { to } \\
697{ }^{\circ} \mathrm{C} \text { working fluid } \\
\text { temperature }\end{array}$ & .1300 & 13 years \\
\hline $\begin{array}{l}\text { Canister with } \\
\text { circumferential void } \\
\text { at } 0 . \text {. wall, engine } \\
\text { cold startup }\end{array}$ & 7.2500 & $\begin{array}{l}0.24 \text { years } \\
\text { or } \\
1400 \text { cycles }\end{array}$ \\
\hline
\end{tabular}




\section{SUMMARY OF RESULTS AND CONCLUSIONS}

The creep-faj.lure criteria had not been defined for the canister. Preliminary NASA Lewis in-house testing of the Haynes-188 alloy has shown that it behaved in a significantly different manner under thermal cyclic loading than under isothermal loading. The design data available for the Haynes-188 alloy are based on monotonic and isothermal loadings. Because of this, further tests and analyses are in progress at NASA Lewis to determine the behavior of the Haynes-188 alloy under thermal cyclic loading. In addition, long-term testing of the canister is being planned. The results from these programs should enable more refined analyses and further improve the design of the canister that will be subjected to repetitive orbital thermal loadings.

The structural performance of a space station TES canister was evaluated analytically and experimentally at various operating conditions. Creep-strain results from structural analyses were used for the structural assessment. The major results of this study are as follows:

1. Creep rupture will most likely be the predominant failure mode for the TES canister (ignoring oxidation and hot corrosion), according to the canister operating thermal environment information provided.

2. Structural performance of the TES canister is sensitive to the saltvoid distribution inside the canister. This is because of the higher peak temperature and stress levels caused by the exact location of the void.

3. Structural performance of the TES canister is sensitive to the thermal environment because creep depends strongly on temperature. Working fluid tempelifurc also has a significant effect on the structural performance of the canister.

4. The existence of a liquid salt pocket inside the canister has no significant effect on the structural performance of the canister because the LiF-CaF 2 salt has a much lower modulus than the Haynes-188 alloy.

5. Additional thermal cyclic testing of Haynes-188 specimens and canisters must be conducted before creep-failure criteria can be defined for the canister.

6. Advanced analytical tools and experimental techniques have been successfully demonstrated for this application. 


\section{REFERENCES}

Anon., 1986, MARC General Purpose Finite Element Program, MARC Analysis Research Corporation, Palo Alto, California.

Anon., 1984, Space Station WP-04 Power System Preliminary Analysis and Design Document, DR02.NAS 3-24666, June 1986, Vol. 1, Section 2, pp. 240-267.

Ellis, J.R., Bartolotta, P.A., and Mladsi, S.W., 1987, "Preliminary Study of Creep Thresholds and Thermomechanical Response in Haynes 188 at Temperatures in the Range $649 \mathrm{C}$ to $871 \mathrm{C}$," Proceedings of the Conference on Turbine Engine Hot Section Technology, NASA CP-2493, pp. 317-334 (FEDD docunent, available to general public after October 1989). 